\title{
HIV-1 integrase resistance among antiretroviral treatment naive and experienced patients from Northwestern Poland
}

\author{
Miłosz Parczewski", Dorota Bander, Anna Urbańska and Anna Boroń-Kaczmarska
}

\begin{abstract}
Background: HIV integrase inhibitor use is limited by low genetic barrier to resistance and possible cross-resistance among representatives of this class of antiretrovirals. The aim of this study was to analyse integrase sequence variability among antiretroviral treatment naive and experienced patients with no prior integrase inhibitor (Inl) exposure and investigate development of the Inl drug resistance mutations following the virologic failure of the raltegravir containing regimen.
\end{abstract}

Methods: Sequencing of HIV-1 integrase region from plasma samples of 80 integrase treatment naive patients and serial samples from 12 patients with observed virologic failure on raltegravir containing treatment whenever plasma vireamia exceeded $>50$ copies $/ \mathrm{ml}$ was performed. Drug resistance mutations were called with Stanford DB database and grouped into major and minor variants. For subtyping bootstrapped phylogenetic analysis was used; Bayesian Monte Carlo Marcov Chain (MCMC) model was implemented to infer on the phylogenetic relationships between the serial sequences from patients failing on raltegravir.

Results: Majority of the integrase region sequences were classified as subtype $B$; the remaining ones being subtype $\mathrm{D}, \mathrm{C}, \mathrm{G}$, as well as CRF01_AE , CRF02_AG and CRF13_cpx recombinants. No major integrase drug resistance mutations have been observed in Inl-treatment naive patients. In 30 (38.5\%) cases polymorphic variation with predominance of the E157Q mutation was observed. This mutation was more common among subtype B (26 cases, 54.2\%) than non-B sequences (5 cases, 16.7\%), $\mathrm{p}=0.00099$, OR: 5.91 (95\% Cl:1.77-22.63)]. Other variants included L68V, L74IL, T97A, E138D, V151I, R263K. Among 12 (26.1\%) raltegravir treated patients treatment failure was observed; major Inl drug resistance mutations (G140S, Q148H and N155H, V151I, E92EQ, V151I, G163R) were noted in four of these cases (8.3\% of the total Inl-treated patients). Time to the development of drug resistance ranged from 2.6 to 16.3 months with mean increase of HIV viral load of 4.34 (95\% Cl:1.86-6.84) log HIV-RNA copies/ml at the time of emergence of the major mutations. Baseline polymorphisms, including E157Q were not associated with the virologic failure on raltegravir.

Conclusions: In Inl treatment naive patients polymorphic integrase sequence variation was common, with no major resistance mutants. In the treatment failing patients selection of drug resistance occurred rapidly and followed the typical drug resistance pathways. Preexisting integrase polymorphisms were not associated with the treatment failure.

Keywords: HIV-1, Integrase inhibitors, Raltegravir, Antiretroviral treatment failure, Drug resistance mutations

\footnotetext{
* Correspondence: mparczewski@yahoo.co.uk

Department of Infectious Diseases and Hepatology, Pomeranian Medical University, Szczecin, Poland
}

\section{Biomed Central}

(c) 2012 Parczewski et al.; licensee BioMed Central Ltd. This is an Open Access article distributed under the terms of the Creative Commons Attribution License (http://creativecommons.org/licenses/by/2.0), which permits unrestricted use, distribution, and reproduction in any medium, provided the original work is properly cited. 


\section{Background}

HIV integrase, being one of the key retroviral enzymes necessary for successful replication, is one of attractive targets in the treatment of HIV infection. Integrase inhibitors, targeting one of the essential steps of the virus life cycle, namely strand transfer have been approved for the clinical practice in 2008, and have proven to be highly efficient in treatment of both antiretroviral-naive and experienced individuals [1-6]. As potent agents, this class of drugs is not only important part of the salvage regimens but is also useful in patients with therapy complications such as lipodystrophy, dyslipidaemia, or liver injury [7-9]. Raltegravir (RAL) is currently licensed in Europe for both treatment naive and experienced patients, elvitregravir pending EMEA approval, while newer compounds such as dolutegravir undergo phase III clinical trials [10-13].

Despite high efficacy observed among treatment experienced patients with drug resistance to other antiretroviral drug classes, low genetic barrier to resistance and possible cross-resistance among integrase inhibitors is a limiting factor in the practical use of these compounds. Virologic failure has been associated with major, signature mutations within the catalytic domain of the enzyme, and include Y143R/C, N155H Q148K/R/H integrase sequence variants associated with significant susceptibility reduction both to RAL and elvitegravir (EVG) [14-19]. Accumulation of secondary, accessory mutants is responsible for the further increase in the level of the resistance and often restored replication capacity [20-22]. Major mutations remain uncommon in the antiretroviral treatment naive patients; so far only a few cases of transmitted drug resistance $(\mathrm{Q} 148 \mathrm{H}$, G140S and N155H mutations) have been described [23,24]. On the other hand, polymorphic mutations in the central core domain positions have been observed in up to $34 \%$ of the published sequences [25] and 56\% of the patients with recently acquired infection [26]; some of these naturally occurring variants have been observed in patients failing raltegravir and elvitegravir (L74M, T97A, S119G/R, E157Q, G163K/R), with notable the frequency variation across the subtypes [4,25,27-31]. Recent reports also describe high frequency of the minority clades bearing major and accessory mutations, however, clinical significance of this pre-existing low level variability is yet to be determined [20,27,32]. Analyses for the secondary drug resistance are currently included in the guidelines for the drug resistance testing among individuals failing integrase containing treatment [33]. This study was designed to investigate the sequence variability in the integrase region with two objectives: firstly, to characterize primary integrase resistance mutations among the treatment naive and experienced patients with no prior integrase inhibitor (InI) exposure; secondly to investigate the development of the InI drug resistance mutations following the virologic failure of the raltegravircontaining regimen.

\section{Methods}

\section{Group characteristics}

In this study HIV-1 integrase sequences from patients observed at the Department of Infectious Diseases and Hepatology Pomeranian Medical University, Szczecin, Poland and Out-Patient's Clinic of Acquired Immunodeficiency, Regional Hospital, Szczecin Poland were obtained. Bioethical committee approval (Bioethical Committee of the Pomeranian Medical University, Szczecin, Poland, approval number KB-0012/08/12) was obtained for this analysis. Informed consent was provided and obtained from study participants. Eighty samples from patients who have never received the integrase inhibitors were selected, including forty-six pretreatment ones from individuals who have later received raltegravir (RAL). Additionally, sequences were obtained at the time of virologic failure on RAL (HIV-RNA levels analysed every four months), whenever such a failure have occurred. Virologic failure was defined as two consecutive viral loads $>50 \mathrm{HIV}$ RNA copies $/ \mathrm{ml}$. To assess adherence number of dispensed monthly doses of antiretroviral medication divided by the number of follow-up months, expressed as a percentage, was used.

\section{Sequencing}

HIV RNA extraction was performed from plasma samples stored at -80 degrees Centigrade using a reagents provided with the Viroseq 2.8 kit (Abbott molecular, Abbott Park, IL, USA). HIV-1 integrase region (866 base pair, HXB2 genome location: positions 4230-5096) was amplified and sequenced with reagents and conditions specified by Laethem et al., and the following amplification and sequencing primers: AGGAGCAGAAACTTWCTATGTA GATGG (outer forward), TTCTTCCTGCCATAGGAR ATGCCTAAG (outer reverse), TTCRGGATYAGAAG TAAAYATAGTAACAG (inner forward), TCCTGTATG CARACCCCAATATG (inner reverse and sequencing), GCACAYAAAGGRATTGGAGGAAATGAAC (sequencing, forward), GGVATTCCCTACAATCCCCAAAG (sequencing, forward), GAATACTGCCATTTGTACTGCTG (sequencing, reverse) [34]. Amplicons obtained by the nested PCR method were used for sequencing by standard techniques with BigDye technology on an ABI 3500 platform (Applied Biosystems, Foster City, CA). Sequence assembly was performed with the Recall online tool (http:// pssm.cfenet.ubc.ca) [35]. For all the InI treated patients both baseline (prior to the raltegravir treatment) and on treatment (at the virologic failure) sequences were obtained. As integrase region sequencing has been initiated in 2011 majority of the samples have been analyzed retrospectively. Integrase sequencing in patients with viral loads $>50$ copies $/ \mathrm{ml}$ was attempted from every available sample, usually collected every four months. All sequences were submitted to GenBank (accession numbers JQ305769-91, KC409134-KC409222). 
Drug resistance, subtyping and phylogenetic analyses

Drug resistance mutations were called with Stanford DB database (hivdb.stanford.edu) and grouped into major and minor mutations as assigned by this on-line tool [36]. For subtyping, phylogenetic analysis with reference sequences listed in the HIV Sequence Compendium 2011 (Los Alamos National Laboratory Los Alamos, USA http://www.hiv.lanl. gov) was used. The sequence dataset was aligned with Clustal X2.0.10 (www.clustal.org). GTR $+\mathrm{I}+\gamma$ substitution model was selected with jmodeltest (software version 0.1.1) based on the lowest akaike information criterion (AIC) $[37,38]$. Base frequencies for the dataset were as follows: $\mathrm{A}=0.4036, \mathrm{C}=0.1613, \mathrm{G}=0.2272, \mathrm{~T}=0.2079, \mathrm{p}$ inv parameter: 0.507 , gamma shape: 0.76 .

Bootstrapped (1000 replicates) maximum composite likelihood (ML) test under the GTR $+\mathrm{I}+\gamma$ model with three separate codon positions, and a nearest-neighbor-interchange ML method was inferred using MEGA 5.05 software. Phylogeny obtained subtype was compared with an on-line subtyping performed by the Stanford DB database. For clarity, phylogenetic trees were divided into subtype $\mathrm{B}$ and non subtype B groups and visualized with the tree explorer included in the MEGA software.

For analysis of the integrase resistance development and phylogenetic relationships between the serially obtained sequences from patients failing on raltegravir containing treatment Bayesian Monte Carlo Marcov Chain (MCMC) analyses were implemented. Two replicates of 100 million generations were run in BEAST v 1.5.3 [39], under the GTR $+\gamma+\Gamma$ model with estimated base frequencies, gamma site heterogenity model, and three partitions for the codon positions. A consensus tree with posterior probabilities for branch support was obtained and annotated with TreeAnnotator $\mathrm{v}$ 1.5.4. Trees were visualized in Figtree v.1.2.2.

For nominal variables chi-square test with EPI6 Statcalc software was used (Department of Mathematics, University of Louisiana-Lafayette, Lafayette, LA, USA), while for continuous variables the Mann-Whitney U-test was implemented (Statistica software, Statsoft, Tulsa, OK, USA).

\section{Results}

\section{Group characteristics}

Majority of the analyzed patients were male, with HIV infection acquired by the heterosexual transmission, with clinical symptoms of immunodeficiency (either B or C according to the CDC classification), baseline lymphocyte CD4 count below 200 cells/ $\mu$ l and HIV-1 viral load exceeding 100000 copies $/ \mathrm{ml}$ (Table 1). Median age at the diagnosis for the entire analysed group was 35 years (IQR:27-45), and 37 years (IQR:26-43) for the RALtreated patients. In twenty cases integrase inhibitor treatment was commenced at undetectable viral load, due to the toxicity of the previous regimen, drug resistance, liver failure or drug interactions.

Integrase sequencing was consistently successful at HIV viral loads exceeding 300 copies $/ \mathrm{ml}$, and one sample of 134 HIV-RNA copies/ml. In two cases the sequencing failed and subtype was unavailable; as the result final dataset for the baseline integrase resistance included the group of 78 individuals.

\section{Subtypes and baseline drug resistance mutations}

Majority of the integrase region sequences were classified as subtype $B$; the remaining ones being subtype $D, C, G$, and recombinants: CRF01_AE, CRF02_AG and CRF13_cpx (Table 1, Figure 1A,B). For all but one sequence concordance between the phylogenetic analysis and Stanford DB assigned subtype was noted but CRF13_cpx recombinant was called subtype $J$ by this on-line tool. In the subtype B infected group injection drug use associated infections were the predominant transmission route (19 cases, 39.6\%), followed by the men who have sex with men (15 cases, 31.2\%) and heterosexual transmissions (13 cases, 27.1\%). For one subtype B infected patient the transmission route remains unknown. For all non-B subtypes heterosexual exposure was noted.

In the InI naive group no major integrase drug resistance mutations have been observed, but in 30 (38.5\%) cases polymorphic variation with minimal influence on integrase inhibitor susceptibility was found, being significantly more common among subtype B sequences (26 cases, $54.2 \%$ ) than non-B ones (5 cases, $16.7 \%$ ), $\mathrm{p}=0.00099$, OR: 5.91 (95\% CI:1.77-22.63) (Figure 1a, 1b). The predominating E157Q polymorphism was found in $47.9 \%$ of the subtype $B$ sequences and associated with injection drug use $(69.6 \%$ of the sequences with E157Q were derived from the IDU patients). This variant was absent in non-B clades. Other mutations and polymorphisms observed only in subtype B integrase sequences were L68V, T97A and V151I, while in non-B sequences R263K, E138D, L68IL and L74IL variants were noted (Figure 1b, Table 1).

\section{Development of Inl drug resistance}

Of the RAL treated patients in twelve cases (26.1\%) treatment failure was observed, with borderline statistical association with non-B subtype [p=0.098, OR: 3.13 (95\% CI:0. 64-15.7)]. In the failing group estimated adherence ranged from the $58 \%$ to $99 \%$. In four cases $(8.3 \%$ of the total number of patients treated with raltegravir, $33.3 \%$ of the failing ones) major InI drug resistance mutations have been observed. Mean viral load on raltegravir treatment in the failing group was 2.79 (95\% CI:2.35-3.22) log HIV-RNA copies/ml being notably higher among patients with developed drug resistance [mean of 3.73 (95\% CI:3.19-4.28) log HIV-RNA copies/ml] compared to the failing ones without 
Table 1 Characteristics of the study population

\begin{tabular}{|c|c|c|}
\hline & Entire group $(n=80)^{*}$ & Patients treated with raltegravir $(n=46)$ \\
\hline Female gender, n (\%) & $34(42.5)$ & $19(41.3)$ \\
\hline \multicolumn{3}{|l|}{ Transmission route } \\
\hline IDU, n (\%) & $19(23.8)$ & $13(28.3)$ \\
\hline Heterosexual, n (\%) & $43(53.8)$ & $22(47.8)$ \\
\hline MSM, n (\%) & $17(21.3)$ & $10(21.7)$ \\
\hline Unknown, n (\%) & $1(1.3)$ & $1(2.2)$ \\
\hline \multicolumn{3}{|l|}{ CDC category at HIV diagnosis } \\
\hline $\mathrm{A}, \mathrm{n}(\%)$ & $23(28.8)$ & $14(30.4)$ \\
\hline $\mathrm{B}, \mathrm{n}(\%)$ & $34(42.5)$ & $19(41.3)$ \\
\hline C, n (\%) & $22(27.5)$ & $14(30.4)$ \\
\hline 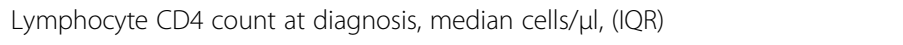 & $147(51-331)$ & $140(29-336)$ \\
\hline Lymphocyte CD4 count prior to raltegravir introduction, median cells/ $\mu \mathrm{I}(\mathrm{IQR})$ & N.A. & $335(154-515)$ \\
\hline \multirow[t]{2}{*}{ HIV viral load at diagnosis, median log HIV-1 copies/ml (IQR) } & $5.33(4.62-5.88)$ & 5.38 \\
\hline & & $(4.62-5.56)$ \\
\hline HIV-RNA undetectable prior to raltegravir introduction, n (\%) & N.A. & $20(44)$ \\
\hline HIV viral load prior to raltegravir introduction, median log HIV-1 copies/ml (IQR) & N.A. & $4.88(3.36-5.44)$ \\
\hline \multicolumn{3}{|l|}{ HIV-1 subtype (integrase coding region) * } \\
\hline $\mathrm{B}, \mathrm{n}(\%)$ & $48(61.5)$ & $30(68.2)$ \\
\hline $\mathrm{D}, \mathrm{n}(\%)$ & $24(30.8)$ & $10(21.7)$ \\
\hline C, n (\%) & $2(2.6)$ & $2(4.5)$ \\
\hline $\mathrm{G}, \mathrm{n}(\%)$ & $1(1.3)$ & 0 \\
\hline CRF01_AE, n (\%) & $1(1.3)$ & $1(2.3)$ \\
\hline CRF02_AG, n (\%) & $1(1.3)$ & $1(2.3)$ \\
\hline CRF13_cpx, n (\%) & $1(1.3)$ & 0 \\
\hline \multicolumn{3}{|l|}{ Baseline integrase polymorphisms * } \\
\hline None, n (\%) & $48(61.5)$ & $24(54.5)$ \\
\hline E157Q , n (\%) & $23(28.8)$ & $15(34.1)$ \\
\hline V1511, n (\%) & $2(3.1)$ & $1(2.3)$ \\
\hline E138D, n (\%) & $2(2.6)$ & 0 \\
\hline T97A, n (\%) & $1(1.3)$ & $1(2.3)$ \\
\hline R263K, n (\%) & $1(1.3)$ & $1(2.3)$ \\
\hline L74IL, n (\%) & $1(1.3)$ & $1(2.3)$ \\
\hline L68V, n (\%) & $1(1.3)$ & $1(2.3)$ \\
\hline
\end{tabular}

*in two cases of raltegravir treated patients the integrase coding region sequencing failed, thus the subtype and interpretation of the baseline integrase polymorphisms was unavailable.

Table legend: IDU: injection drug use, MSM - men who have sex with men, IQR - interquartile range.

the InI drug resistance mutations [mean: 2.79 (95\% CI:2.35 -3.22) log HIV-RNA copies/ml] ( $\mathrm{p}=0.0079$, Figure 2 ).

Baseline polymorphisms, including the most prevalent E157Q analyzed separately, were not associated with the virologic failure on $\mathrm{RAL}$ [p=0.5, OR 1.56 (95\% CI: 0.35-7.11) and $\mathrm{p}=0.38$, OR 1.83 (95\% CI:0.38-10.05), respectively]. In 14 cases with virologic success accessory mutations were present prior to the raltegravir introduction (11 sequences with E157Q, one of each L68V/E157Q, T97A, V151I). Among virologically failing patients E157Q was noted in one patient with $\mathrm{N} 155 \mathrm{H}$ mutant, in three E157Q variant was present at baseline and consistently in the sequences obtained on RAL therapy while in two patients either R263K or L74IL were present at baseline and disappeared in the subsequent sequences on virologically unsuccessful treatment.

Development of drug resistance mutations followed two patterns: major $\mathrm{N} 155 \mathrm{H}$ with or without subsequent accessory V151I, E92EQ, V151I, G163R mutants (three cases) and Q148H accompanied by G140S mutant (one 

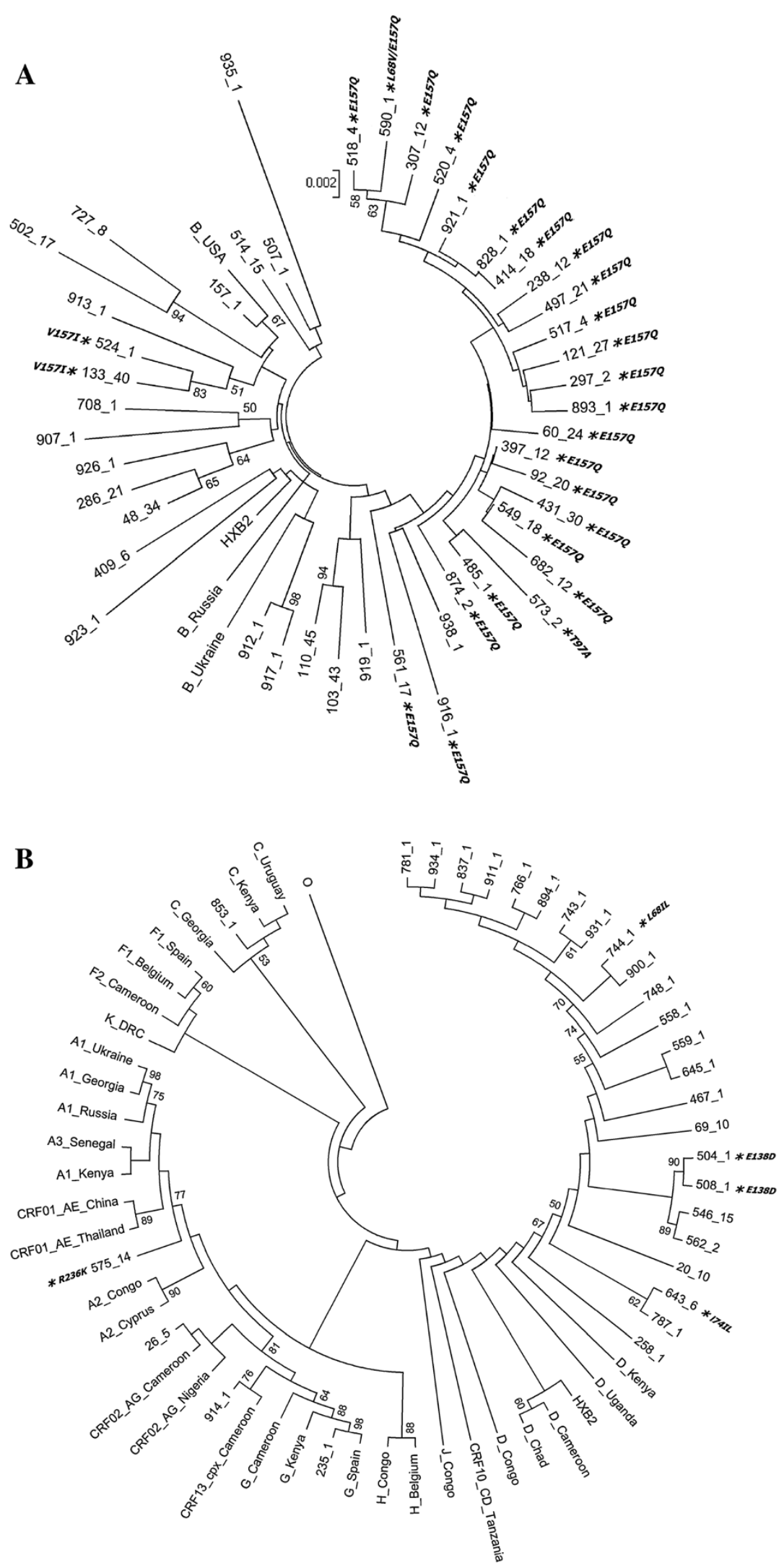

Figure 1 (See legend on next page.) 
(See figure on previous page.)

Figure 1 Maximum composite likelihood inferred trees showing phylogenetic relationships of subtype B (A) and non-subtype B isolates to the HIV-1 M group reference strains. Bootstrap values, expressed as percentage, are listed at the branch nodes. Baseline integrase mutations are listed alongside patient number following an asterisk.

case) (Figure 3B). To determine the intra-patient relationships between the mutations we have also used a time-annotated phylogenetic Bayesian Monte Carlo Marcov Chain analysis rooted with the pretreatment samples (Figure 3A). Time to the development of drug resistance ranged from the 2.6 to 16.3 months with mean increase of the HIV viral load (available for patients 1-3) of 4.34 (95\% CI:1.86-6.84) log HIV-RNA copies $/ \mathrm{ml}$ at the time point of emergence of the major drug resistance mutations.

It must be noted, that three of the patients with developed drug resistance were heavily experienced with reverse transcriptase (RT) and protease (PR) mutations (patient 1: RT: M41L, K103N, M184V, T215S; PR: L10I; patient 2: PR: M41L, V118I, K103N, M184V, L210W, T215S, RT: L10I, M46I, I54V, L63P, A71T, V82A, L90M, patient 4: RT: K103N, M184V, P225H, F227L), while one patient (number 3) due to endocarditis and kidney failure was treated with live-saving but suboptimal therapy which consisted solely of ritonavir-boosted saquinavir and raltegravir.

\section{Discussion}

Integrase inhibitors remain an attractive option and have become a vital component of the modern antiretroviral treatment, especially among patients with preexisting drug resistance or treatment complications [2,40-45]. It is necessary to monitor the transmission and de novo development of drug resistance mutations decreasing the susceptibility of HIV against this class of antiretrovirals to provide the virologists and clinicians with the current data allowing for adequate therapeutic strategies.

In the presented study, among the InI naive patients no major drug resistance mutations have been observed, however, accessory mutations have been common (38.5\%). Of the noted variants, four (L68V, T97A, V151I, E157Q) have previously been described as polymorphic, occurring in $>1 \%$ of integrase sequences [25]. These integrase mutations were more prevalent in the subtype B viruses with E157Q occurring at higher frequencies than previously reported [46-50]. In the previous reports this polymorphism was shown to impair the integrase 3/end processing and strand transfer [17] but was associated with only minimal reduction of the susceptibility to RAL and elvitegravir ( $<6$ fold) $[25,26,51,52]$. Of note, in our study the E157Q mutation was observed mostly among phylogenetically related subtype B infected intravenous drug users (Figure 1A), and was not associated with higher ratio of the virological failure. This is the largest described so far cluster with this polymorphism in subtype B infected patients. Lack of clinically important, primary resistance mutations for raltegravir, elvitegravir and dolutegravir is consistent with published reports from other studies [27,47,53-59], and is supports the fact

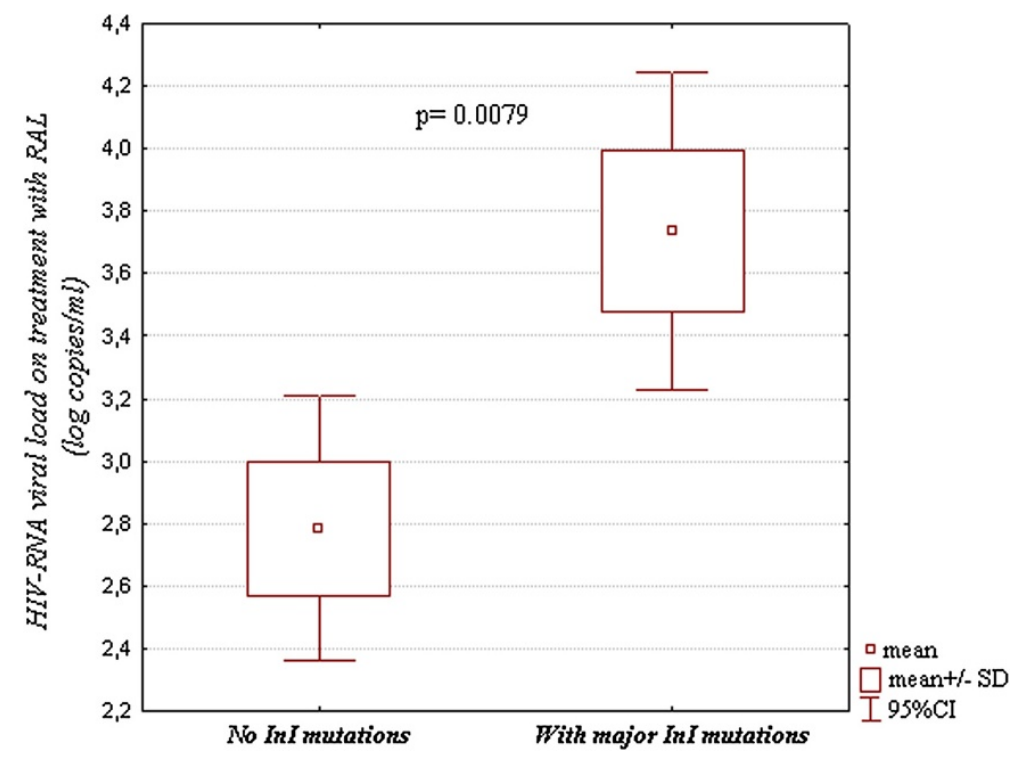

Figure 2 HIV-1 viral loads in the group failing raltegravir containing treatment with and without observed Inl drug resistance mutations. 


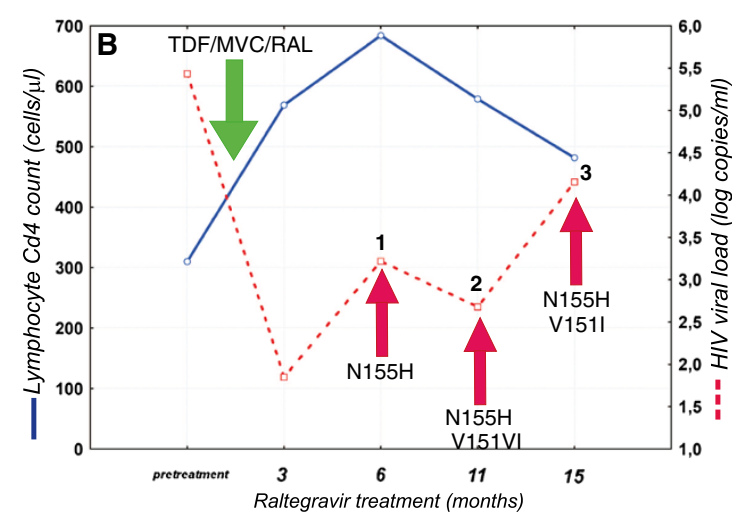

Patient 2:

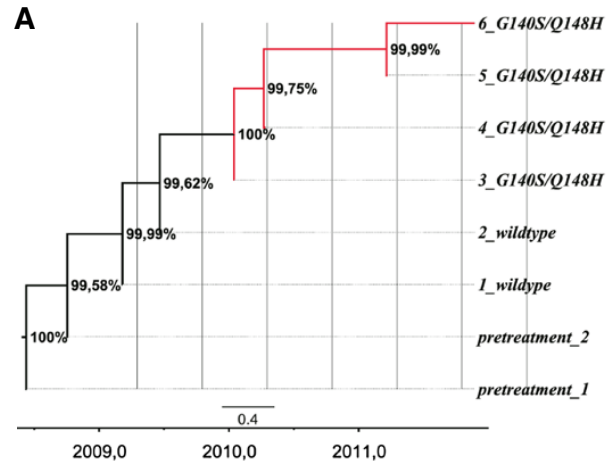

Patient 3:

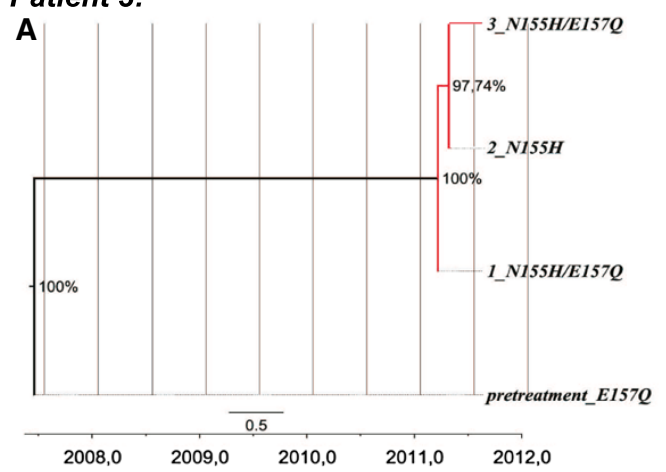

Patient 4:

A

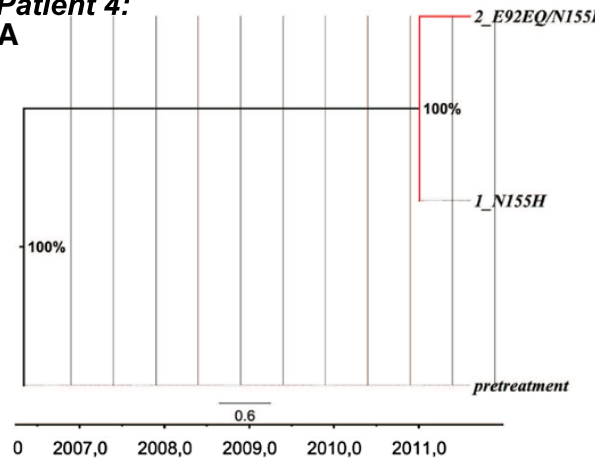

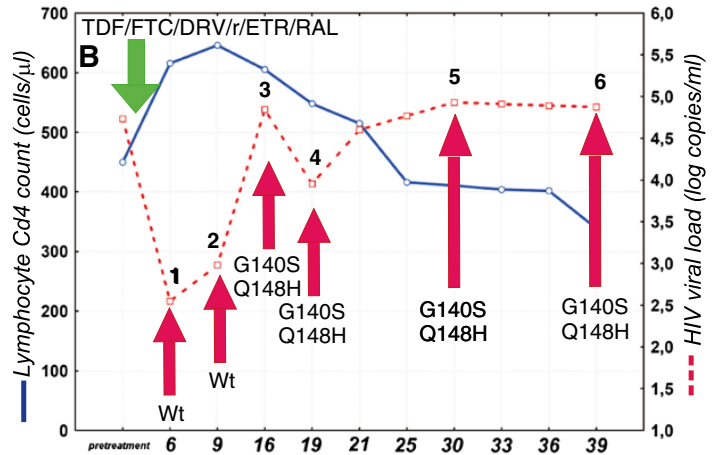
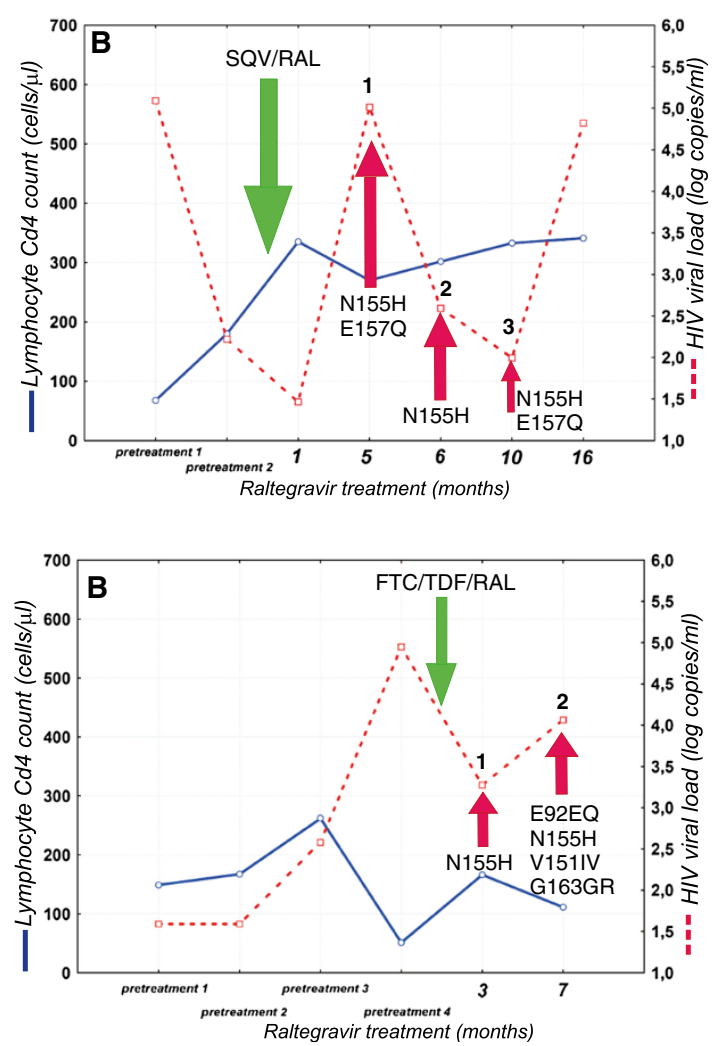

Figure 3 (See legend on next page.) 
(See figure on previous page.)

Figure 3 (A) Phylogenetic trees (time-annotated MCMC) of the serial sequences and (B) HIV-1 viral loads and lymphocyte CD4 counts from four patients failing raltegravir (RAL) treatment. Maximum likelihood tree with bootstrap values for 1000 replicates drawn at the tree branches. Integrase resistance mutations are marked at the tip nodes; branches with developed drug resistance are marked red. Time points in which Inl drug resistance mutations were noted are indicated with red arrows, while initiation of the raltegravir containing antiretroviral treatment is indicated with green arrow. TDF - tenofovir, MVC- maraviroc, FTC - emticitabine, DRV/r - ritonavir boosted darunavir, SQV saquinavir.

that the transmission of the drug resistance is unlikely in the populations previously unexposed to the integrase inhibitor treatment [60].

In the group of the RAL treated patients treatment was successful in $73.9 \%$ of cases, while the $8.3 \%$ of the failing patients developed major drug resistance mutations significantly reducing susceptibility to both raltegravir and elvitegravir. Number of virologic failures was higher than observed in the STARTMRK and BENCHMRK trials for the patients with high baseline genotypic scores $[1,5,6,15]$, however, in the analysed group integrase inhibitor was usually considered as a second line treatment and was selected due to toxicity, drug resistance or drug-drug interactions, as well as preexisting drug resistance in treatment experienced patients; suboptimal adherence was also commonly noted - only in three (one described below with developed integrase resistance mutations and two with integraseinhibitor susceptible variants) failing patients estimated adherence exceeded $90 \%$. Another reason for the high frequency of treatment failure on raltegravir-containing regimen may be related to the preexisting drug resistance mutations in the reverse transcriptase region resulting in the lower susceptibility to the background regimen. NRTI drug resistance mutations (thymidyne analog mutations and $\mathrm{M} 184 \mathrm{~V}$ ) were present in six (50\%) of the twelve treatment failing patients prior to RAL introduction. Additionally, treatment efficacy was numerically worse among nonB subtypes (with borderline statistical significance), however this may be associated with small group size as in the previous reports raltegravir was comparably efficacious across B and non-B HIV-1 subtypes [4].

Integrase drug resistance profiles in four treatment failing patients with drug resistance followed two typical pathways, Q148H/G140S (one case) and N155H/V151I (three patients), associated with high level resistance to raltegravir and cross-resistance to elvitegravir [16-18,61,62]. Similar cases have been described previously $[19,61,63]$. Of note, in the patient with the Q148H/G140S salvage treatment option with dolutegravir was also lost due to the resistance associated with this pathway [64]. As expected, in cases observed in our study virologic rebound was associated with significant increase of the plasma viral load at the time-point of the occurrence of the major mutation. Stepwise accumulation of mutations was observed in two patients with $\mathrm{N} 155 \mathrm{H}$ followed by the secondary E92Q, V151I and/or G163R mutations resulting in further increase raltegravir and elvitegravir resistance and often enhanced replicative capacity $[27,65]$. All observed mutations have been previously associated with raltegravir drug resistance observed in in vivo studies [15,45]. The N155H pathway is also associated with smaller reduction in the RAL susceptibility than the Q148H, moreover, double Q148H/G140S mutants were found to be fitter than the E92Q/N155H ones [66,67]. This is consistent with the observed higher viral loads at the time of the development of drug resistance in a patient 2 (if compared to the patients $1,3,4)$ in whom such a highly fit double mutant was observed (Figure 3). In the patient 3 the observed drug resistance is probably associated with the suboptimal treatment and poor drug exposure when combined only with boosted saqinavir, however no other treatment option was possible for the patient at the time of therapy initiation . Time to InI resistance development in the observed patients did not exceed few months, except for one case with the double Q148H/G140S mutant, which is in accordance to the data on the low genetic barrier for the integrase inhibitors and rapid selection of the resistant variants $[15,68]$.

\section{Conclusions}

In summary, the results of this study provide data for the clinical practice and the treatment with integrase inhibitors. No major mutations associated with integrase dug resistance have been found in the pretreatment samples, however the polymorphic variation was common. In the failing patients selection of drug resistance occurred rapidly, and followed the typical pathways with accumulation of the drug resistance. Poor adherence, preexisting drug resistance and suboptimal combination were the key reasons associated with the development of the drug resistance.

\section{Competing interests \\ The authors declare that they have no competing interests related to this study.}

\section{Authors' contributions}

Conceived and designed the study: MP. Performed the experiments and analyses: MP AU. Analyzed the data: MP. Contributed reagents/materials/ analysis tools: MP AU. Statistical and phylogenetic analyses: MP. Wrote the paper: MP DB AU ABK. All authors read and approved the final manuscript.

\section{Acknowledgements}

The study was supported by the project of the Polish Ministry of Science IUVENTUS PLUS IP2011 040071. The funders had no role in study design, 
data collection and analysis, decision to publish, or preparation of the manuscript. The Authors would like to thank the stuff of Out-Patient's Department, Regional Hospital, Szczecin for the support of this study.

Received: 27 August 2012 Accepted: 18 December 2012 Published: 21 December 2012

\section{References}

1. Steigbigel RT, Cooper DA, Kumar PN, Eron JE, Schechter M, Markowitz M, Loutfy MR, Lennox JL, Gatell JM, Rockstroh JK, et al: Raltegravir with optimized background therapy for resistant HIV-1 infection. N Engl J Med 2008, 359(4):339-354.

2. Gatell JM: The use of integrase inhibitors in treatment-experienced patients. Eur J Med Res 2009, 14(Suppl 3):30-35.

3. Nguyen BY, Isaacs RD, Teppler $H$, Leavitt RY, Sklar P, Iwamoto $M$, Wenning $L A$, Miller MD, Chen J, Kemp R, et al: Raltegravir: the first HIV-1 integrase strand transfer inhibitor in the HIV armamentarium. Ann N Y Acad Sci 2011, 1222:83-89.

4. Rockstroh JK, Teppler H, Zhao J, Sklar P, Miller MD, Harvey CM, Strohmaier KM, Leavitt RY, Nguyen BY: Clinical efficacy of raltegravir against $B$ and non-B subtype HIV-1 in phase III clinical studies. AIDS 2011, 25(11):1365-1369.

5. Lennox JL, DeJesus E, Lazzarin A, Pollard RB, Madruga JV, Berger DS, Zhao J, Xu X, Williams-Diaz A, Rodgers AJ, et al: Safety and efficacy of raltegravirbased versus efavirenz-based combination therapy in treatment-naive patients with HIV-1 infection: a multicentre, double-blind randomised controlled trial. Lancet 2009, 374(9692):796-806.

6. Lennox JL, Dejesus E, Berger DS, Lazzarin A, Pollard RB, Ramalho Madruga JV, Zhao J, Wan H, Gilbert CL, Teppler H, et al: Raltegravir versus Efavirenz regimens in treatment-naive HIV-1-infected patients: 96-week efficacy, durability, subgroup, safety, and metabolic analyses. J Acquir Immune Defic Syndr 2010, 55(1):39-48.

7. Correll T, Klibanov OM: Integrase inhibitors: a new treatment option for patients with human immunodeficiency virus infection. Pharmacotherapy 2008, 28(1):90-101

8. Grant P, Zolopa A: Integrase inhibitors: a clinical review of raltegravir and elvitegravir. J HIV Ther 2008, 13(2):36-39.

9. Hughes A, Barber T, Nelson M: New treatment options for HIV salvage patients: an overview of second generation PIs, NNRTIs, integrase inhibitors and CCR5 antagonists. J Infect 2008, 57(1):1-10.

10. Boyd M: Dolutegravir-a promising antiretroviral in development. Lancet Infect Dis 2012, 12(2):90-91.

11. Blanco JL, Martinez-Picado J: HIV integrase inhibitors in ART-experienced patients. Curr Opin HIV AIDS 2012, 7(5):415-421.

12. Cocohoba J, Dong BJ: Raltegravir: the first HIV integrase inhibitor. Clin Ther 2008, 30(10):1747-1765.

13. Cotelle P: Patented HIV-1 integrase inhibitors (1998-2005). Recent Pat Antiinfect Drug Discov 2006, 1(1):1-15.

14. Miller M: Resistance to integrase inhibitors. J HIV Ther 2007, 12(4):101.

15. Cooper DA, Steigbigel RT, Gatell JM, Rockstroh JK, Katlama C, Yeni P, Lazzarin A, Clotet B, Kumar PN, Eron JE, et al: Subgroup and resistance analyses of raltegravir for resistant HIV-1 infection. N Engl J Med 2008, 359(4):355-365.

16. Goethals $\mathrm{O}$, Clayton R, Van Ginderen M, Vereycken I, Wagemans E, Geluykens P, Dockx K, Strijbos R, Smits V, Vos A, et al: Resistance mutations in human immunodeficiency virus type 1 integrase selected with elvitegravir confer reduced susceptibility to a wide range of integrase inhibitors. J Virol 2008, 82(21):10366-10374.

17. Malet I, Delelis O, Valantin MA, Montes B, Soulie C, Wirden M, Tchertanov L, Peytavin G, Reynes J, Mouscadet JF, et al: Mutations associated with failure of raltegravir treatment affect integrase sensitivity to the inhibitor in vitro. Antimicrob Agents Chemother 2008, 52(4):1351-1358.

18. Roquebert B, Blum L, Collin G, Damond F, Peytavin G, Leleu J, Matheron S, Chene G, Brun-Vezinet F, Descamps D: Selection of the Q148R integrase inhibitor resistance mutation in a failing raltegravir containing regimen AIDS 2008, 22(15):2045-2046.

19. Canducci F, Sampaolo M, Marinozzi MC, Boeri E, Spagnuolo V, Galli A, Castagna A, Lazzarin A, Clementi M, Gianotti N: Dynamic patterns of human immunodeficiency virus type 1 integrase gene evolution in patients failing raltegravir-based salvage therapies. AIDS 2009, 23(4):455-460.
20. Ferns RB, Kirk S, Bennett J, Cook PM, Williams I, Edwards S, Pillay D: The dynamics of appearance and disappearance of HIV-1 integrase mutations during and after withdrawal of raltegravir therapy. AIDS 2009, 23(16):2159-2164.

21. Canducci F, Marinozzi MC, Sampaolo M, Boeri E, Spagnuolo V, Gianotti N, Castagna A, Paolucci S, Baldanti F, Lazzarin A, et al: Genotypic/phenotypic patterns of HIV-1 integrase resistance to raltegravir. J Antimicrob Chemother 2010, 65(3):425-433.

22. Ceccherini-Silberstein F, Malet I, Fabeni L, Dimonte S, Svicher V, D'Arrigo R, Artese A, Costa G, Bono S, Alcaro S, et al: Specific HIV-1 integrase polymorphisms change their prevalence in untreated versus antiretroviral-treated HIV-1-infected patients, all naive to integrase inhibitors. J Antimicrob Chemother 2010, 65(11):2305-2318.

23. Boyd SD, Maldarelli F, Sereti I, Ouedraogo GL, Rehm CA, Boltz V, Shoemaker D, Pau AK: Transmitted raltegravir resistance in an HIV-1 CRF_AG-infected patient. Antivir Ther 2011, 16(2):257-261.

24. Young B, Fransen S, Greenberg KS, Thomas A, Martens S, St Clair M, Petropoulos CJ, Ha B: Transmission of integrase strand-transfer inhibitor multidrug-resistant HIV-1: case report and response to raltegravircontaining antiretroviral therapy. Antivir Ther 2011, 16(2):253-256.

25. Rhee SY, Liu TF, Kiuchi M, Zioni R, Gifford RJ, Holmes SP, Shafer RW: Natural variation of HIV-1 group $M$ integrase: implications for a new class of antiretroviral inhibitors. Retrovirology 2008, 5:74.

26. Low A, Prada N, Topper M, Vaida F, Castor D, Mohri H, Hazuda D, Muesing M, Markowitz M: Natural polymorphisms of human immunodeficiency virus type 1 integrase and inherent susceptibilities to a panel of integrase inhibitors. Antimicrob Agents Chemother 2009, 53(10):4275-4282

27. Ceccherini-Silberstein F, Van Baelen K, Armenia D, Trignetti M, Rondelez E, Fabeni L, Scopelliti F, Pollicita M, Van Wesenbeeck L, Van Eygen V, et al: Secondary integrase resistance mutations found in HIV-1 minority quasispecies in integrase therapy-naive patients have little or no effect on susceptibility to integrase inhibitors. Antimicrob Agents Chemother 2010, 54(9):3938-3948.

28. Ceccherini-Silberstein F, Malet I, D'Arrigo R, Antinori A, Marcelin AG, Perno CF: Characterization and structural analysis of HIV-1 integrase conservation. AIDS Rev 2009, 11(1):17-29.

29. Armenia D, Vandenbroucke I, Fabeni L, Van Marck H, Cento V, D'Arrigo R, Van Wesenbeeck L, Scopelliti F, Micheli V, Bruzzone B, et al: Study of Genotypic and Phenotypic HIV-1 Dynamics of Integrase Mutations During Raltegravir Treatment: A Refined Analysis by Ultra-Deep 454 Pyrosequencing. J Infect Dis 2012, 205(4):557-567.

30. Fish MQ, Hewer R, Wallis CL, Venter WD, Stevens WS, Papathanasopoulos MA: Natural polymorphisms of integrase among HIV type 1-infected South African patients. AIDS Res Hum Retroviruses 2010, 26(4):489-493.

31. Garrido C, Geretti AM, Zahonero N, Booth C, Strang A, Soriano V, De Mendoza C: Integrase variability and susceptibility to HIV integrase inhibitors: impact of subtypes, antiretroviral experience and duration of HIV infection. J Antimicrob Chemother 2010, 65(2):320-326.

32. Charpentier C, Laureillard D, Piketty C, Tisserand P, Batisse D, Karmochkine M, Si-Mohamed A, Weiss L: High frequency of integrase Q148R minority variants in HIV-infected patients naive of integrase inhibitors. AIDS 2010, 24(6):867-873

33. Vandamme AM, Camacho RJ, Ceccherini-Silberstein F, de Luca A, Palmisano L, Paraskevis D, Paredes R, Poljak M, Schmit JC, Soriano V, et al: European recommendations for the clinical use of HIV drug resistance testing: 2011 update. AIDS Rev 2011, 13(2):77-108.

34. Van Laethem K, Schrooten Y, Covens K, Dekeersmaeker N, De Munter P, Van Wijngaerden E, Van Ranst M, Vandamme AM: A genotypic assay for the amplification and sequencing of integrase from diverse HIV-1 group $M$ subtypes. J Virol Methods 2008, 153(2):176-181.

35. Harrigan PR DW, Wynhoven B, Mo T, Hall T, Galli R: The Performance of ReCall basecalling software for high-throughput HIV drug resistance basecalling using "in-house" methods, XIV International AIDS Conference, Spain, Barcelona Abstract \#TuPeB4598.; 2002

36. Liu TF, Shafer RW: Web resources for HIV type 1 genotypic-resistance test interpretation. Clin Infect Dis 2006, 42(11):1608-1618.

37. Guindon S, Dufayard JF, Lefort V, Anisimova M, Hordijk W, Gascuel O: New algorithms and methods to estimate maximum-likelihood phylogenies: assessing the performance of PhyML 3.0. Syst Biol 2010, 59(3):307-321.

38. Posada D: jModelTest: phylogenetic model averaging. Mol Biol Evol 2008, 25(7):1253-1256. 
39. Drummond AJ, Rambaut A: BEAST: Bayesian evolutionary analysis by sampling trees. BMC Evol Biol 2007, 7:214

40. Tseng A, Foisy M: Important Drug-Drug Interactions in HIV-Infected Persons on Antiretroviral Therapy: An Update on New Interactions Between HIV and Non-HIV Drugs. Curr Infect Dis Rep 2012, 14(1):67-82.

41. Lampiris HW: Elvitegravir: a once-daily, boosted, HIV-1 integrase inhibitor. Expert Rev Anti Infect Ther 2012, 10(1):13-20.

42. Katlama C, Murphy R: Dolutegravir for the treatment of HIV. Expert Opin Investig Drugs 2012, 21(4):523-530.

43. Arts EJ, Hazuda DJ: HIV-1 Antiretroviral Drug Therapy. Cold Spring Harb Perspect Med 2012, 2(4):a007161.

44. Powderly WG: Integrase inhibitors in the treatment of HIV-1 infection. J Antimicrob Chemother 2010, 65(12):2485-2488.

45. Gatell JM, Katlama C, Grinsztejn B, Eron JJ, Lazzarin A, Vittecoq D, Gonzalez $\mathrm{CJ}$, Danovich RM, Wan H, Zhao J, et al: Long-term efficacy and safety of the HIV integrase inhibitor raltegravir in patients with limited treatment options in a Phase II study. J Acquir Immune Defic Syndr 2010, 53(4):456-463.

46. Turriziani O, Montagna C, Falasca F, Bucci M, Russo G, Lichtner M, Sobze MS, Vullo V, Pistello M, Antonelli G: Analysis of the Integrase Gene from HIV Type 1-Positive Patients Living in a Rural Area of West Cameroon. AIDS Res Hum Retroviruses 2012, 28(12):1729-1733.

47. Oliveira MF, Ramalho DB, Abreu CM, Vubil A, Mabunda N, Ismael N, Francisco C, Jani IV, Tanuri A: Genetic Diversity and Naturally Polymorphisms in HIV Type 1 Integrase Isolates from Maputo Mozambique: Implications for Integrase Inhibitors. AIDS Res Hum Retroviruses 2012, 28(12):1788-1792.

48. Nouhin J, Donchai T, Hoang KT, Ken S, Kamkorn J, Tran T, Ayouba A, Peeters M, Chaix ML, Lien TX, et al: Natural polymorphisms of HIV-1 CRF01_AE integrase coding region in ARV-naive individuals in Cambodia, Thailand and Vietnam: an ANRS AC12 working group study. Infect Genet Evol 2011, 11(1):38-43.

49. Kumar A, Jadhav C: Genotypic prediction of resistant mutation in HIV-1 pol gene towards the antiretroviral drugs. Int J Bioinform Res Appl 2011, 7(1):15-23.

50. Varghese V, Liu TF, Rhee SY, Libiran P, Trevino C, Fessel WJ, Shafer RW: HIV1 integrase sequence variability in antiretroviral naive patients and in triple-class experienced patients subsequently treated with raltegravir. AIDS Res Hum Retroviruses 2010, 26(12):1323-1326.

51. Goethals O, Vos A, Van Ginderen M, Geluykens P, Smits V, Schols D, Hertogs $\mathrm{K}$, Clayton R: Primary mutations selected in vitro with raltegravir confer large fold changes in susceptibility to first-generation integrase inhibitors, but minor fold changes to inhibitors with second-generation resistance profiles. Virology 2010, 402(2):338-346.

52. Reuman EC, Bachmann MH, Varghese V, Fessel WJ, Shafer RW: Panel of prototypical raltegravir-resistant infectious molecular clones in a novel integrase-deleted cloning vector. Antimicrob Agents Chemother 2010, 54(2):934-936

53. Saladini F, Meini G, Bianco C, Monno L, Punzi G, Pecorari M, Borghi V, Di Pietro M, Filice G, Gismondo MR, et al: Prevalence of HIV-1 integrase mutations related to resistance to dolutegravir in raltegravir naive and pretreated patients. Clin Microbiol Infect 2012, 18(10):E428-E430.

54. Monleau M, Aghokeng AF, Nkano BA, Chaix ML, Peeters M: Drug resistance mutations of HIV-1 non-B viruses to integrase inhibitors in treatmentnaive patients from sub-Saharan countries and discordant interpretations. AIDS Res Hum Retroviruses 2012, 28(29):1157-1160

55. Mantovani NP, Azevedo RG, Rabelato JT, Sanabani S, Diaz RS, Komninakis SV: Analysis of Transmitted Resistance to Raltegravir and Selective Pressure among HIV-1-Infected Patients on a Failing HAART in Sao Paulo, Brazil. J Clin Microbiol 2012, 50(6):2122-2125.

56. Luu QP, Dean J, Do TT, Carr MJ, Dunford L, Coughlan S, Connell J, Hien NT WWH, Nguyen Thi LA: HIV-1 Coreceptor Tropism, CCR5 Genotype and Integrase Inhibitor Resistance Profiles in Vietnam - Implications for the Introduction of New Antiretroviral Regimens. AIDS Res Hum Retroviruses 2012, 28(10):1344-1348.

57. Winslow DL: Resistance to HIV integrase inhibitors. AIDS Alert 2011 26(9):106-107

58. Phuphuakrat A, Pasomsub E, Kiertiburanakul S, Chantratita W, Sungkanuparph S: HIV Type 1 Integrase Polymorphisms in TreatmentNaive and Treatment-Experienced HIV Type 1-Infected Patients in
Thailand Where HIV Type 1 Subtype A/E Predominates. AIDS Res Hum Retroviruses 2011, 28(8):937-943.

59. Rangel HR, Garzaro D, Fabbro R, Martinez N, Ossenkop J, Torres JR, Gutierrez CR, Pujol FH: Absence of primary integrase resistance mutations in HIV type 1-infected patients in Venezuela. AIDS Res Hum Retroviruses 2010, 26(8):923-926.

60. van Hal SJ, Herring B, Deris Z, Wang B, Saksena NK, Dwyer DE: HIV-1 integrase polymorphisms are associated with prior antiretroviral drug exposure. Retrovirology 2009, 6:12.

61. Charpentier C, Karmochkine M, Laureillard D, Tisserand P, Belec L, Weiss $L$, Si-Mohamed A, Piketty C: Drug resistance profiles for the HIV integrase gene in patients failing raltegravir salvage therapy. HIV Med 2008, 9(9):765-770.

62. Kobayashi M, Nakahara K, Seki T, Miki S, Kawauchi S, Suyama A, WakasaMorimoto C, Kodama M, Endoh T, Oosugi E, et al: Selection of diverse and clinically relevant integrase inhibitor-resistant human immunodeficiency virus type 1 mutants. Antiviral Res 2008, 80(2):213-222.

63. da Silva D, Van Wesenbeeck L, Breilh D, Reigadas S, Anies G, Van Baelen K, Morlat P, Neau D, Dupon M, Wittkop L, et al: HIV-1 resistance patterns to integrase inhibitors in antiretroviral-experienced patients with virological failure on raltegravir-containing regimens. J Antimicrob Chemother 2010, 65(6):1262-1269.

64. Vavro C, Dudas K, Hasan S, Huang J, Yeo Y, Underwood M: Dolutegravir Treatment of HIV Subjects With Raltegravir Resistance: Integrase Resistance Evolution in Cohort II of the VIKING Study, "International Workshop on HIV \& Hepatitis Virus Drug Resistance and Curative Strategies; June 5-9, 2012; Sitges, Spain", Abstract 3.; 2012.

65. Blanco JL, Varghese V, Rhee SY, Gatell JM, Shafer RW: HIV-1 Integrase Inhibitor Resistance and Its Clinical Implications. J Infect Dis 2011, 203(9):1204-1214.

66. Fransen S, Gupta S, Frantzell A, Petropoulos CJ, Huang W: Substitutions at Amino Acid Positions 143, 148 and 155 of HIV-1 Integrase Define Distinct Genetic Barriers to Raltegravir Resistance in vivo. J Virol 2012, 86(13):7249-7255.

67. Hu Z, Kuritzkes DR: Effect of raltegravir resistance mutations in HIV-1 integrase on viral fitness. J Acquir Immune Defic Syndr 2010, 55(2):148-155.

68. Hatano H, Lampiris H, Fransen S, Gupta S, Huang W, Hoh R, Martin JN, Lalezari J, Bangsberg D, Petropoulos C, et al: Evolution of integrase resistance during failure of integrase inhibitor-based antiretroviral therapy. J Acquir Immune Defic Syndr 2010, 54(4):389-393.

doi:10.1186/1471-2334-12-368

Cite this article as: Parczewski et al:: HIV-1 integrase resistance among antiretroviral treatment naive and experienced patients from Northwestern Poland. BMC Infectious Diseases 2012 12:368

\section{Submit your next manuscript to BioMed Central and take full advantage of:}

- Convenient online submission

- Thorough peer review

- No space constraints or color figure charges

- Immediate publication on acceptance

- Inclusion in PubMed, CAS, Scopus and Google Scholar

- Research which is freely available for redistribution

Submit your manuscript at www.biomedcentral.com/submit
C Biomed Central 